\title{
PYROLYSIS OF BROWN COAL USING A CATALYST BASED ON W-Ni
}

\author{
Lenka Jílková ${ }^{a, *}$, Karel Ciahotný ${ }^{a}$, Jaroslav KusÝ ${ }^{b}$ \\ a Department of Gas, Coke and Air Protection, Institute of Chemical Technology Prague, Technická 5, Prague \\ 166 28, Czech Republic \\ ${ }^{b}$ Brown Coal Research Institute, Budovateli 2830, Most 434 37, Czech Republic \\ * corresponding author: Lenka. Jilkova@vscht.cz
}

\begin{abstract}
Tars from pyrolysis of brown coal can be refined to obtain compounds suitable for fuel production. However, it is problematic to refine the liquids from brown coal pyrolysis, because high molecular compounds are produced, and the sample solidifies. Therefore we decided to investigate the possibility of treating the product in the gas phase during pyrolysis, using a catalyst. A two-step process was investigated: thermal-catalytic refining. In the first step, alumina was used as the filling material, and in the second step a catalyst based on W-Ni was used. These materials were placed in two separate layers above the coal, so the volatile products passed through the alumina and catalyst layers.

Pyrolysis tests showed that using the catalyst has no significant effect on the mass balance, but it improves the properties of the gas and the properties of the organic part of the liquid pyrolysis products, which will then be processed further.
\end{abstract}

KEYWORDS: catalytic pyrolysis; W-Ni catalyst; brown coal.

\section{INTRODUCTION}

The pyrolysis products of brown coal are [1, 2]:

(1.) a solid pyrolysis residue, referred to as coke or semi-coke, which is used as a fuel or as an adsorbent;

(2.) a liquid product, which consists of an organic part and a water part and can be utilized as a fuel after refining;

(3.) a gas, which is often used for heating a reactor.

The highest yields of liquid products can be achieved by fast pyrolysis, in which the products are rapidly removed from the pyrolysis reactor [3]. The properties of the liquid product are closely related to the material properties and the process conditions [4. Unlike the yield of coke, the yield of volatile matter increases as the pyrolysis temperature increases. Increasing the residence time of the volatile product in the hot area leads to secondary reactions, such as thermal cracking, polymerization and condensation, which reduce theF yield of the liquid product [5, 6]. Substances containing sulphur, nitrogen and oxygen allow easier thermal decomposition, all of which leads to the formation of carbon dioxide, carbon monoxide, ammonia, hydrogen sulphide, pyrogenetic water and other products [1].

When the material is being heated, typical processes take place [7, 8]:

(1.) evaporation of water and desorption of adsorbed gases (up to $150{ }^{\circ} \mathrm{C}$ );

(2.) the onset of thermal decomposition, formation of the first hydrocarbon gases, $\mathrm{CO}_{2}, \mathrm{CO}$ and $\mathrm{H}_{2} \mathrm{~S}$ $\left(150-300^{\circ} \mathrm{C}\right)$;
(3.) formation of tar, $\mathrm{CH} 4$ and higher hydrocarbons $\left(300-400^{\circ} \mathrm{C}\right)$;

(4.) ongoing thermal decomposition of organic matter, formation of hydrogen and pyrolysis carbon (semicoke) $\left(400-600^{\circ} \mathrm{C}\right)$;

(5.) tar formation comes to an end, decomposition of organic matter to hydrogen and carbon continues $\left(600-1000^{\circ} \mathrm{C}\right)$.

The organic part of the liquid can be used for fuel production. After pyrolysis, the organic part must be separated out from the liquid product contaminated by water. The organic product must be hydrogenated to decompose the compounds with a high molecular weight, because these compounds can cause the sample to solidify. This can be achieved by using a catalyst during pyrolysis. After hydrogenation, or pyrolysis with the catalyst, the organic liquid product has properties similar to those of petroleum. This suggests that these products could also be processed in refineries for conversion to engine fuel [3].

\section{MATERIAL AND METHODS}

\subsection{Pyrolysis apPaRATUS}

The pyrolysis apparatus (Fig. 1) was placed in the laboratory of the Brown Coal Research Institute in Most.

The batch $(500 \mathrm{~g})$ was poured into a metal retort, which was placed in an electrically heated furnace. In the retort, $2 \mathrm{~cm}$ above the coal, there was a stainless steel grid, where the alumina (a layer $1.5 \mathrm{~cm}$ in thickness) or the alumina and the catalyst (a layer $1.5 \mathrm{~cm}$ 


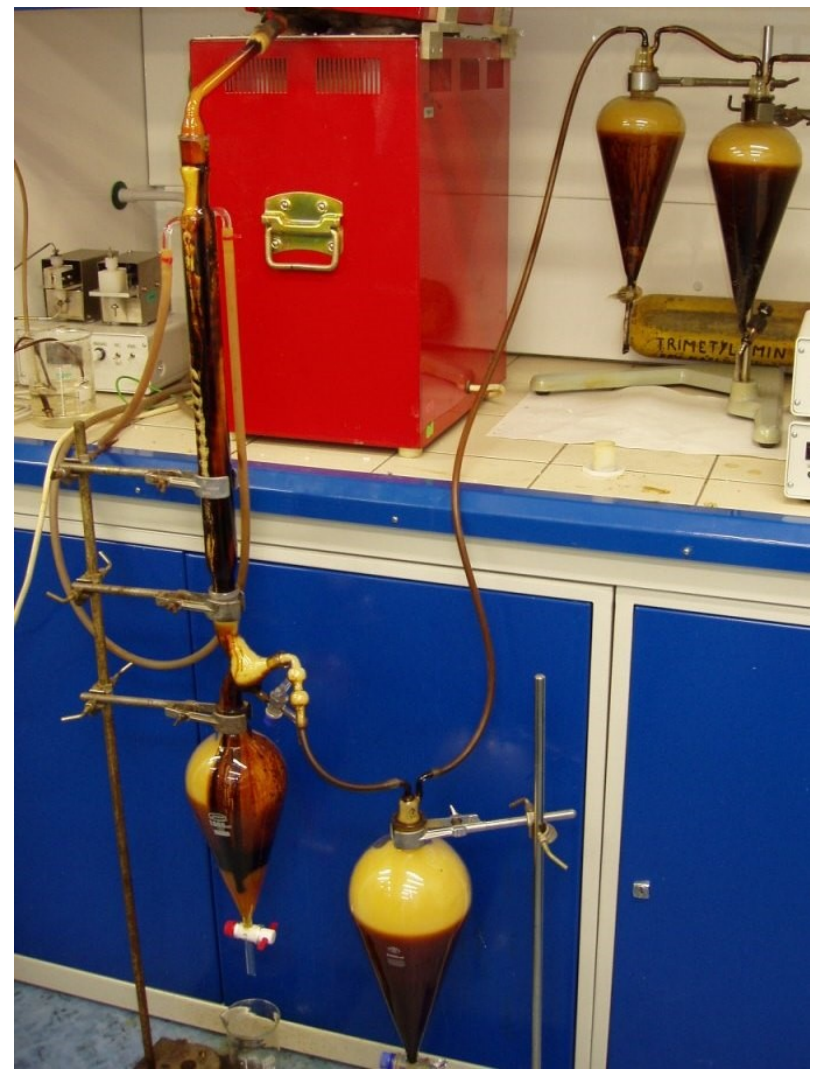

Figure 1. Pyrolysis apparatus: 1-furnace, 2-water cooler, 3-separators, 4-sampling bag or gas burner.

in thickness plus a layer $1 \mathrm{~cm}$ in thickness) was placed. The retort was heated to $650^{\circ} \mathrm{C}\left(8.93^{\circ} \mathrm{C} \mathrm{min}^{-1}\right)$, and the temperature was maintained for 3 hours. The system was purged by $20-30 \mathrm{dm}^{3}$ of nitrogen, when the temperature in the reactor was $200{ }^{\circ} \mathrm{C}$. The volatile compounds that were generated were conducted into a water cooler, then into four serially connected separators, where the liquid condensate was accumulated. The pyrolysis gas was collected in a sampling bag when the temperature in the pyrolysis reactor was already $510^{\circ} \mathrm{C}$, and was analyzed using GC $82 \mathrm{TT}$ (Labio Praha) a few minutes later. The redundant pyrolysis gas was burned in a gas burner. After each pyrolysis test, a mass balance was performed and an analysis was made of the liquid products (using GC HP 6890 coupled with a mass detector).

\begin{tabular}{lcc}
\hline \multicolumn{1}{c}{ Substance } & & Part [wt \%] \\
\hline Analytical water & $W_{\mathrm{a}}$ & 6.9 \\
Analytical ash & $A_{\mathrm{a}}$ & 5.3 \\
Sulphur in a dry sample & $S_{\mathrm{d}}$ & 1.0 \\
Carbon in a dry sample & $C_{\mathrm{d}}$ & 74.6 \\
Volatile flammable & & \\
$\quad$ in a dry sample & $V_{\mathrm{d}}$ & 57.7 \\
Combustion heat & $Q_{\mathrm{s}}$ & 31.3 \\
\hline
\end{tabular}

TABle 1. Properties of the brown coal.

\subsection{BROWN COAL FOR PYROLYSIS}

Brown coal from the CSA mine was used as the feedstock. The basic properties of the brown coal are shown in Table 1

For the tests on the pyrolysis apparatus the following were used: brown coal; brown coal with alumina; brown coal with alumina and a catalyst based on $\mathrm{W}-\mathrm{Ni}$.

\subsection{Analytical methods}

Off-line analysis of pyrolysis gases. The pyrolysis gases were collected in sampling bags, and were analyzed immediately, using GC 82TT LABIO Praha with a dual thermal conductivity detector (TCD). Hydrogen, oxygen, nitrogen, methane and carbon monoxide were determined by the first TCD $\left(150^{\circ} \mathrm{C}\right.$, stainless steel column: length $2 \mathrm{~m}$, diameter $3.2 \mathrm{~mm}$, stationary phase: molecular sieve $5 \mathrm{~A}$, carrier gas: argon). Carbon dioxide was determined by the second TCD $\left(150^{\circ} \mathrm{C}\right.$, teflon column: length $2 \mathrm{~m}$, diameter $3.2 \mathrm{~mm}$, stationary phase: Porapak Q, carrier gas: helium).

Off-line analysis of the water and the organic part of the pyrolysis condensate. The liquid products were analyzed qualitatively, using GC HP 6890 with a mass detector (MSD 5973). The gas chromatographer had an MTX-1 metallic column (length $30 \mathrm{~m}$, diameter $250 \mu \mathrm{m}$, carrier gas helium). The column was at a temperature of $50^{\circ} \mathrm{C}$ for first two minutes, and then the temperature was raised to $320^{\circ} \mathrm{C}\left(15^{\circ} \mathrm{C} \mathrm{min}^{-1}\right)$. A temperature of $320^{\circ} \mathrm{C}$ was maintained for the next five minutes.

\begin{tabular}{|c|c|c|c|c|c|c|}
\hline & \multicolumn{2}{|c|}{ Brown coal } & \multicolumn{2}{|c|}{$\begin{array}{l}\text { Brown coal } \\
+ \text { alumnia }\end{array}$} & \multicolumn{2}{|c|}{$\begin{array}{l}\text { Brown coal }+ \\
\text { alumnia }+ \text { catalyst }\end{array}$} \\
\hline & Mass $[\mathrm{g}]$ & Part [wt \%] & Mass $[\mathrm{g}]$ & Part [wt \%] & Mass [g] & Part [wt \%] \\
\hline Batch & 500 & 100 & 500 & 100 & 500 & 100 \\
\hline Semi-coke & 257.14 & 51.43 & 258.93 & 51.79 & 259.51 & 51.9 \\
\hline Water part of the tar & 110.5 & 22.1 & 107.71 & 21.54 & 114 & 22.79 \\
\hline Organic part of the tar & 25.14 & 5.03 & 24 & 4.8 & 18.48 & 3.7 \\
\hline Gas + Losses & - & 21.44 & - & 21.87 & - & 21.61 \\
\hline
\end{tabular}

TABLE 2. Mass balance of brown coal pyrolysis; brown coal with alumina; brown coal with alumina and the catalyst. 


\begin{tabular}{lccc}
\hline & Brown coal & $\begin{array}{c}\text { Brown coal } \\
+ \text { alumina }\end{array}$ & $\begin{array}{c}\text { Brown coal }+ \\
\text { alumina }+ \text { catalyst }\end{array}$ \\
\hline Hydrogen & 0.65 & 1.31 & 10.73 \\
Oxygen & 1.2 & 0.89 & 0.51 \\
Nitrogen & 7.57 & 6.04 & 5.7 \\
Carbon monoxide & 10.71 & 12.46 & 14.8 \\
Methane & 6.84 & 8.52 & 9.68 \\
Carbon dioxide & 38.47 & 39.12 & 35.84 \\
Ethene & 0.13 & 0.31 & 0.41 \\
Ethane & 0.42 & 1.3 & 1.51 \\
Propene & 0.33 & 0.45 & 0.48 \\
Propane & 0.5 & 0.65 & 0.82 \\
\hline
\end{tabular}

TABle 3. Composition of the pyrolysis gases, in vol \%.

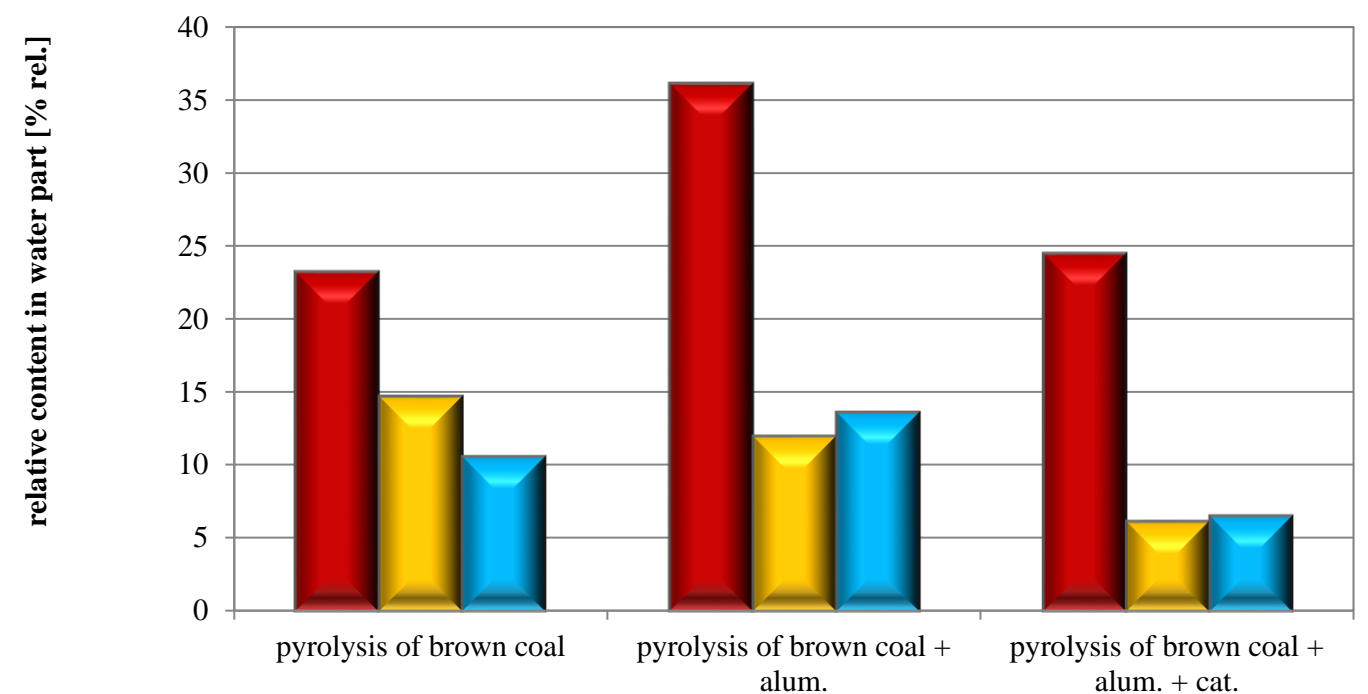

区phenol

囚1,2-benzenediol

区acetic acid

Figure 2. Content of phenol, 1,2-benzenediol and acetic acid in the water parts of the pyrolysis condensates.

\section{Results AND DisCUSSION}

\subsection{MASS BALANCE}

Table 2 presents the mass balances of individual pyrolysis events. It shows that the use of alumina or alumina with the catalyst has no major effect on the mass balance. The only exception is the organic part of the condensate, which decreased from $5.03 \mathrm{wt} \%$ (brown coal) to $4.80 \mathrm{wt} \%$ (brown coal with alumina), and then to $3.70 \mathrm{wt} \%$ (brown coal with alumina and the catalyst).

\subsection{Composition of Pyrolysis Gases}

Table 3 presents the results of an analysis of the pyrolysis gases. The analysis showed that the content of hydrogen, carbon monoxide and methane in the pyrolysis gas increased significantly when the catalyst was used. At the same time, the content of nitrogen and carbon dioxide in the pyrolysis gas decreased.

\subsection{COMPOSITION OF THE WATER PARTS OF THE PYROLYSIS CONDENSATE}

In each sample of the water part of the pyrolysis condensate, about 25 compounds were identified by the GC-MS method. These were mostly polar compounds, such as phenol, 1,2-benzenediol and acetic acid. Figure 2, below, shows the contents of these three compounds in the water parts of the pyrolysis condensates. The relative contents in percentages $(y-$ axis) in the graphs are in fact the percentages of the peak area for the respective compound, according to the total peak area for the analyzed sample.

The graph in Fig. 2 shows that the use of alumina and the catalyst during pyrolysis of brown coal decreased the content of 1,2-benezenediol in the water part. There is no clear trend for phenol and acetic acid. A significant trend is revealed when we compare the compounds according to the functional groups, see Fig. 3. There is an increasing content of phenols, unlike the content of acids and aromatic alcohols with two $\mathrm{OH}^{-}$groups. 


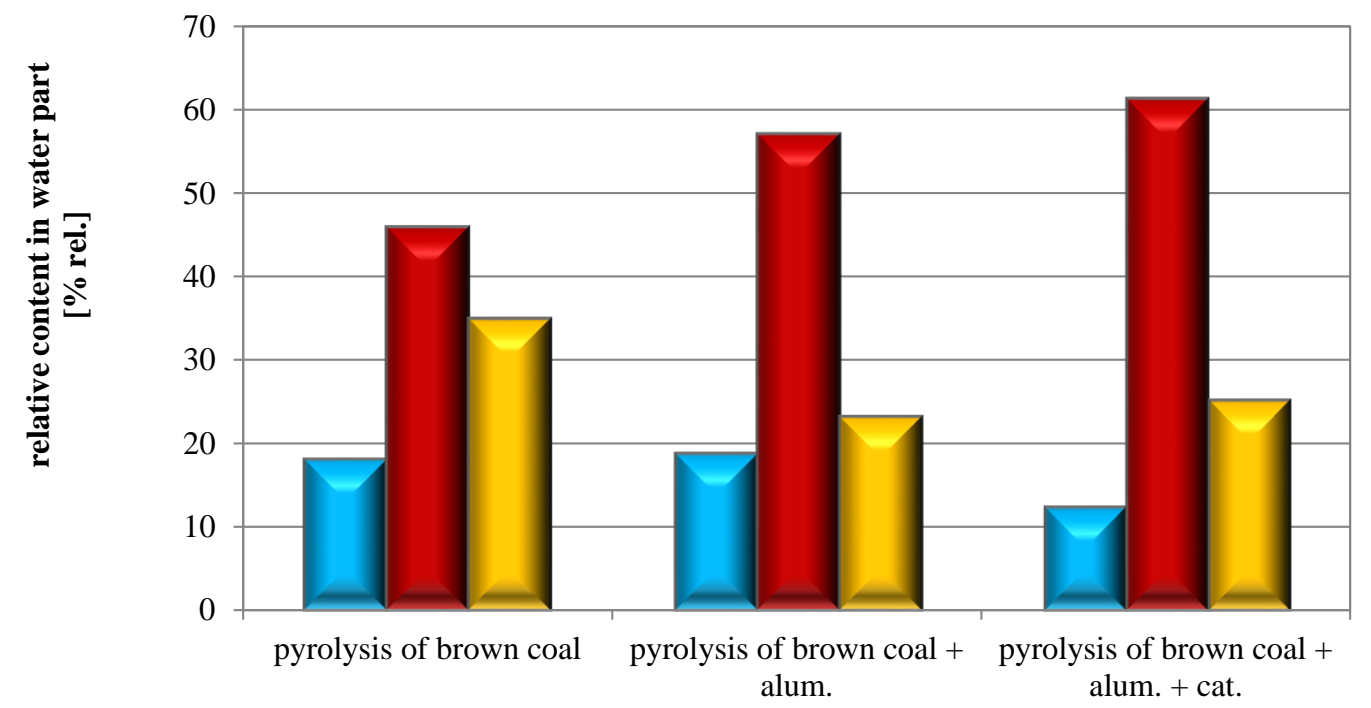

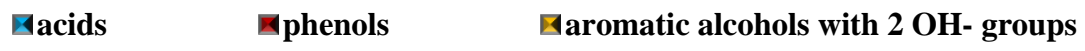

FiguRE 3. Content of compounds (selected according to functional groups) in the water parts of the pyrolysis condensates.

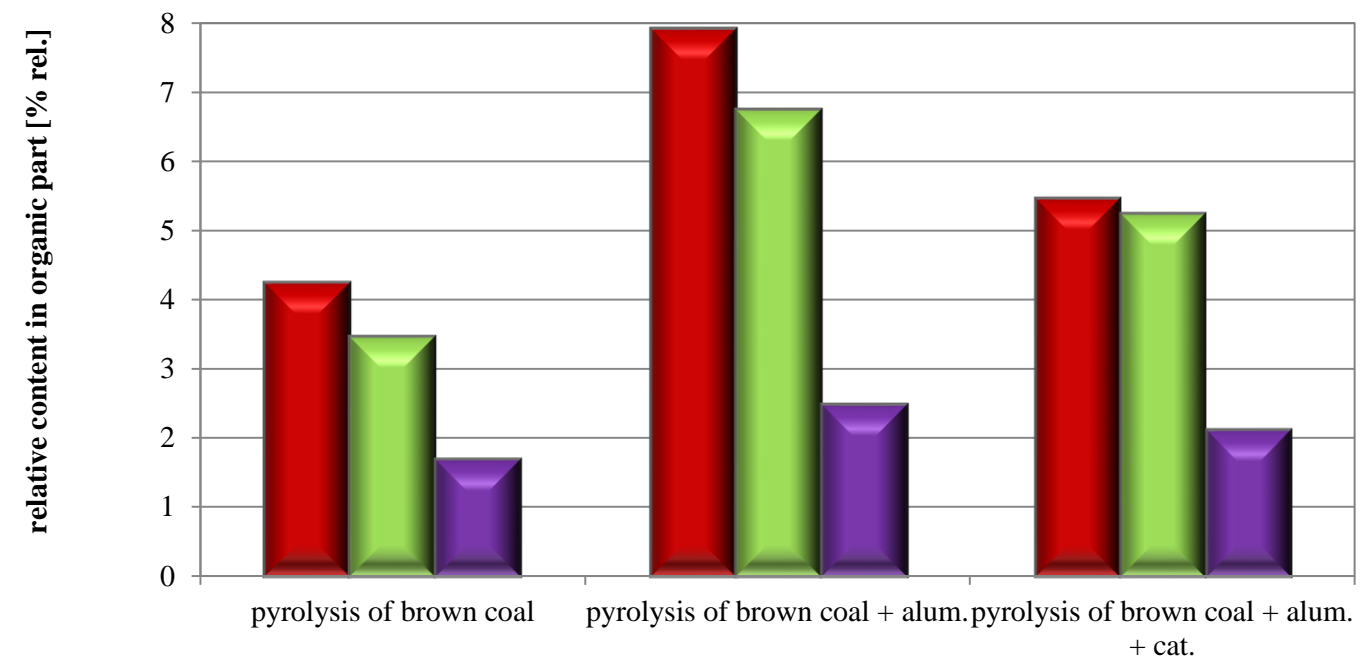

Qphenol Q4-methylphenol Q2,4-dimethylphenol

FigURE 4. Content of phenol, 4-methylphenol and 2,4-dimethylphenol in the organic parts of the pyrolysis condensates.

\subsection{COMPOSITION OF THE ORGANIC PARTS OF THE PYROLYSIS CONDENSATE}

Over 100 compounds were identified by the GC-MS method in each sample of the organic part of the pyrolysis condensate. The compounds that were identified include phenol, 4-methylphenol, and 2,4dimethylphenol. Figure 4 shows content of these three compounds in the organic parts of the pyrolysis condensates. The relative contents as a percentage (y-axis) in the graphs are in fact the percentages of the peak area for the respective compound, according to the total peak area for the analyzed sample.

The graph in Fig. 4 shows that the highest content of identified phenols is for the organic part of the condensate from pyrolysis of brown coal with alumina. A clear trend is apparent from the comparison of compounds selected according to functional groups. When alumina or alumina with the catalyst is used, the content of phenols decreases during pyrolysis, whereas the content of aromatic and aliphatic hydrocarbons increases slightly.

The decrease in phenols and in substituted phenols content may be attributed to a positive influence of the catalyst on the hydrogenation of the phenols, even if the operating conditions were not optimal for the catalyst (a low temperature in the incipient phase of pyrolysis). 


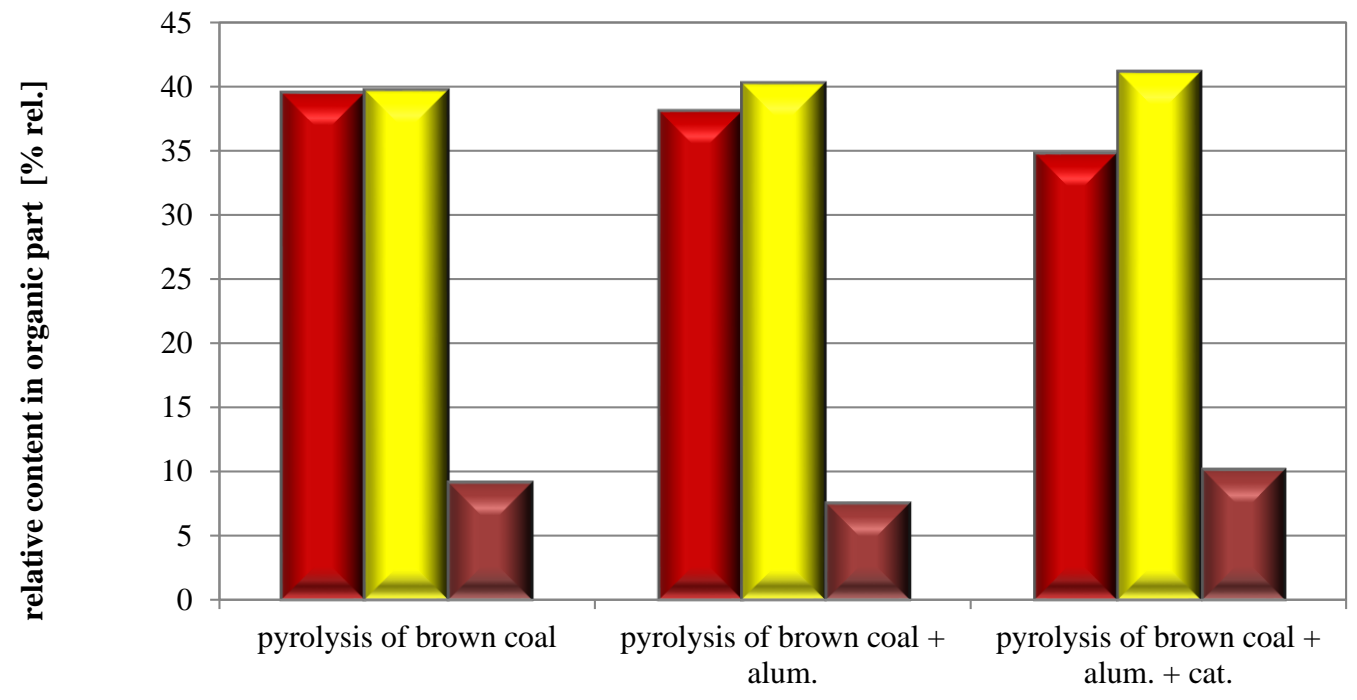

国phenols

Øaromatic hydrocarbons

Qaliphatic hydrocarbons

Figure 5. Content of compounds (selected according to functional groups) in the organic parts of the pyrolysis condensates.

\subsection{Conclusions}

The use of alumina, or alumina with the catalyst, during pyrolysis of brown coal has no major effect on the mass balance, but it improves the gas properties and the properties of the organic part of the liquid pyrolysis products, which are then further processed.

The content of hydrogen, carbon monoxide and methane in the pyrolysis gas increased significantly when the catalyst was used during pyrolysis. However, the content of nitrogen and carbon dioxide in the pyrolysis gas decreased. The increasing content of hydrogen supports desirable reactions in the pyrolysis reactor, leading to better properties of the organic part that are useful for refining.

The decrease in phenols and substituted phenol content may be attributed to the positive influence of the catalyst on the hydrogenation of phenols, even if the operating conditions were not optimal for the catalyst (a low temperature in the incipient phase of pyrolysis). The catalyst should be placed in a separately heated reactor, leading to a further decrease in the phenol content.

\section{ACKNowledGements}

Financial support from specific university research (MSMT No 20/2013).

\section{REFERENCES}

[1] A. Procházková, J. Káňa, J. Kusý, K. Ciahotný, L. Jílková, V. Vrbová: Aprochem 2011, Kouty nad Desnou 11. - 13. 4. 2011, 1. part, p. 305-312, Kouty nad Desnou, 2011.

[2] G. K. Janssens, G. Reggers, H. Pastijn, J. Yperman, M. Jans, M. Stals, R. Carleer, S. Schreurs, T. Cornelissen, T. Kuppens, T. Thewys: J. Anal. Appl. Pyrolysis, 85, 87-97 (2009), DOI: 10.1016/j.jaap.2008.12.003.

[3] R. H. Venderbosch, W. Prins: Biofuels, Bioprod. Biorefin., 6, 178-208 (2010), DOI: 10.1002/bbb.205.

[4] W. Gerhartz: Ullman's Encyclopedia of Industrial Chemistry, part A7, VCH, 5. ed., Weinheim 1986.

[5] H. Knoetze, J. Gorgens, M. Carrier, T. Hugo: J. Anal. Appl. Pyrolysis, 90, 12-26 (2011), DOI: 10.1016/j.jaap.2010.10.001.

[6] R. He, Y. Chen: J. Anal. Appl. Pyrolysis, 90, 72-79 (2011), DOI: 10.1016/j.jaap.2010.10.007.

[7] R. Riedl, V. Veselý: Technologie paliv. SNTL, Praha 1962.

[8] S. Landa: Paliva a jejich využití. SNTL, Praha 1956. 